\title{
The Role of Organizational Capacity in Student-Athlete Development
}

\author{
Emily J. Andrassy \\ Independent Scholar
}

Per Svensson

University of Louisville

\author{
Jennifer Bruening \\ University of Connecticut \\ Matt R. Huml \\ University of Louisville
}

\section{Michael Chung \\ University of Vermont}

\begin{abstract}
In-depth interviews were conducted with the life skills coordinators of 9 of 21 institutions identified as being "dedicated" to service (Andrassy \& Bruening, 2011). As a result of service being one portion of CHAMPS/Life Skills programming, we expanded our investigation to include all aspects of this student development program. In particular, we focused our inquiry on organizational capacity and its role in student involvement. Findings indicate these 'dedicated' athletic departments were characterized by strong organizational capacity for engaging student-athletes in meaningful service efforts. The critical role of coaches and mutual values among internal stakeholders emerged as the primary strengths of department's human resources capacity. Despite the limited financial capacity, departments were able to creatively secure some funding for development programs. The ability to leverage external relationships, an organizational culture promoting participative decisionmaking and student-athlete development, and on-going efforts to improve service and life skills opportunities for student-athletes indicated strong structural capacity.
\end{abstract}

Launching the Challenging Athletes' Minds for Personal Success (CHAMPS)/ Life Skills program in 1991 marked the NCAA's formal recognition that student involvement has become an academic priority in today's higher education institutions. The program, with its focus on five aspects of student-athlete development: academic commitment, career development commitment, athletics commitment, personal development commitment, and service commitment (NCAA, 2007), acknowledges that college students enjoy opportunities to engage in their college

\footnotetext{
Andrassy is an independent scholar living in San Diego, CA. Bruening is with the Dept. of Educational Leadership, University of Connecticut, Storrs, CT. Svensson is with the Dept. of Sport Management, University of Louisville, Louisville, KY. Huml is with Education Advising Student Services, University of Louisville, Louisville, KY. Chung is with the Dept. of Medicine, University of Vermont, Burlington, VT. Address author correspondence to Jennifer Bruening at jennifer.bruening@uconn.edu.
} 
experiences (Pascarella \& Terenzini, 1991, 2005), while also making future career connections (Clary, Snyder, \& Ridge, 1992). Student involvement efforts can promote personal and social responsibility among student-athletes. For instance, increased community service involvement has shown to help increase academic, social, and life skills development (Astin, 1999; Astin \& Sax, 1998). According to Astin $(1984 ; 1999)$ and colleagues (Astin \& Sax, 1998), college students need to become active participants in their own learning. Higher education practitioners should take a supplementary role in how students will develop while in college instead of focusing on what they will develop (Astin, 1984).

Astin's Student Involvement Theory (1984, 1993, 1999; Astin \& Sax, 1998) suggests that when college students become active participants in their college experience they can "achieve the effects intended" (Astin, 1984 p. 522; i.e., academic and life skills development). Warner and Dixon (2013) interviewed recreational student-athletes about community service involvement and reported the athletes' engagement was purely voluntary and driven primarily by intrinsic motives. However, opportunities for engagement are organized for the students and promoted by faculty and staff. Although Warner and Dixon's (2013) focused on recreation sport participants, their work provides support for the use of Astin's Student Involvement Theory (1984) among varsity sport participants as well.

Most studies examining student-athlete involvement rely on self-reported questionnaires from student-athletes discussing their own experiences (Gayles \& Hu, 2009; Gayles, Rockenbach, \& Davis, 2012; Kuh, 2001; Richard \& Aries, 1999; Umbach, Palmer, Kuh, \& Hannah, 2006). Beyond the direct role of the student-athletes, these studies also indicate the influence of environmental factors on student-athlete development. Intercollegiate athletic departments are increasingly emphasizing student-athlete development; however, connections between mission and mission fulfillment are not always clear (Andrassy \& Bruening, 2011). For instance, departments who state that student-athlete development is central to their mission are not always willing or able to commit the resources necessary to provide a quality program. And, while individual athletes can be motivated intrinsically to become actively involved in their own development, organizational support must also exist to reach the large numbers of student-athletes on college campuses. As such, examining student-athlete involvement must be combined with an understanding of the athletic department's ability to set and achieve its goals and objectives, or its organizational capacity.

Organizational capacity reflects "the ability of an organization to harness its internal and external resources to achieve its goals" (Misener \& Doherty, 2013, p.136). Hall, Andrukow, Barr, Brock, de Wit, and Embuldeniya (2003) provide an organizational capacity framework that consists of three dimensions: human resources, financial resources, and structural capacity. The latter consists of three subdimensions: relationships and networks, infrastructure and process, and planning and development. The ability of an athletic department to achieve its goals is influenced by the attitudes, knowledge and skills of its organizational members (i.e., administrators, staff, and student-athletes). Human resources capacity-an organization's ability to deploy human capital - is also considered crucial for the development of the remaining dimensions of organizational capacity (Hall et al., 2003). However, student-athlete development programs require more than simply human resources to be effective and sustainable (Fulks, 2013; Nite, 2012). 
Financial resources capacity refers to an organization's ability to attract and expend diverse sources of financial capital to create stability (Hall et al., 2003; Misener \& Doherty, 2009; Wicker \& Breuer, 2011, 2013; Wicker, Breuer, \& Hennigs, 2012). Athletic departments with limited funding for student-athlete development can increase their capacity through building interorganizational partnerships both on campus and in the communities that surround the campus to manage scarce resources. The process of building and maintaining partnerships, and the impacts of these partnerships is considered an organization's relationship and network capacity (Hall, et al., 2003). In contrast to external partnerships, infrastructure and process capacity are the internal structures necessary for organizational capacity. Examples include internal communication systems and an organizational culture (Hall et al., 2003). According to literature on organizational empowerment (e.g., Peterson \& Zimmerman, 2004), athletic departments should also establish shared values and beliefs among staff and student-athletes to assist in achieving organizational goals. Leaders within the department also need to provide meaningful opportunities and personal responsibility to student-athletes while creating a collaborative work environment, in which staff and student-athletes support each other. This calls for organizational planning and development capacity (e.g., strategic plans, program design, and evaluation of organizational practices; Hall et al., 2003).

Simply put, the ability of an athletic department to mobilize internal and external resources to achieve its mission is considered organizational capacity (Hall et al., 2003). While organizations with larger numbers of resources may have greater organizational capacity, this is not always the case (Eisinger, 2002). In this study, we aim to better understand the factors necessary to sustain the highest levels of student-athlete development. Specifically, what are the practices of athletic departments with a high level of involvement in student-athlete development programs? We seek to provide insight into two aspects of CHAMPS/Life Skills programs: individual (student-athletes and staff members) and organizational (university and athletic department).

\section{Conceptual Framework}

\section{Student Involvement}

In the last thirty years student engagement literature has become focused on the importance of ensuring students stay involved on-campus and the surrounding communities (e.g., Astin, 1984, 1993, 1999; Astin \& Sax, 1998; Kuh, Cruce, Shoup, Kinzie, \& Gonyea, 2008; Pascarella \& Terenzini, 2005). While Astin focused on the general student population, more recent research has been conducted on student-athlete involvement (Bowen \& Levin, 2011; Gayles \& Hu, 2009; Gayles et al., 2012; Kamusoko \& Pemberton, 2011, 2013; Pascarella \& Terenzini, 1991, 2005; Shulman \& Bowen, 2001; Umbach et al., 2006; Valentine \& Taub, 1999). The findings remain inconsistent regarding potential differences between involvement among student-athletes and the general student population. Research on studentathlete involvement on campuses and in communities has shown that they are likely to reap many of the tangible benefits the general student population receives. These benefits include personal satisfaction, learning new skills, social connections, social responsibility, improvement in academics, and learning about their community 
(Chalk, 2008; Gayles \& Hu, 2009). Student-athletes have also shown to be more aware of the need to be involved in developmental activities than the general student population, but studies question their commitment to put this awareness into action (Gayles et al., 2012; Shulman \& Bowen, 2001). In response, student-athletes have voiced potential challenges with being involved on-campus and in the community due to the lack of time availability outside of athletic obligations (Kamusoko \& Pemberton) or possible dependence on their coaching staff to personally connect them with developmental opportunities (Jarvie \& Paule-Koba, 2012).

\section{NCAA CHAMPS/Life Skills Programming}

One means of exposing student-athletes to developmental opportunities while taking into account barriers of time and access is the CHAMPS/Life Skills program. The CHAMPS/Like Skills mission consists of five aspects of student-athlete development: academic commitment, career development commitment, athletics commitment, personal development commitment, and service commitment (NCAA, 2007).

Academic commitment entails providing the student-athlete with necessary support for academic achievement. This includes assistance with orientation, registration, developing studying skills, time management, and scholarship applications. Time management is an important issue in intercollegiate athletics due to the NCAA limits on time spent on sport (Benford, 2007).

Career development commitment focuses on how student-athletes can deal with sport agents as well as transitioning from their sport to a future nonathletic career. This aspect also introduces athletes to job search processes. Murphy, Petitpas, and Brewer (1996) highlighted the importance for student-athletes to explore educational opportunities and an identity outside of sport to avoid delayed career development.

Athletics commitment emphasizes improving leadership skills and learning how to deal with coaches and lack of playing time. A positive, healthy relationship between student-athletes and their coaches has shown to increase student-athlete happiness (Lafrenière, Jowett, Vallerand, \& Carbonneau, 2011). On the other hand, a lack of trust from student-athletes in their coaches can lead to a decrease in wellbeing (Blanchard, Amiot, Perreault, Vallerand, \& Provencher, 2009).

Personal development commitment focuses on nutrition, stress management, personal finances, drugs and alcohol, and diversity. Financial literacy has become an important topic in regards to professional athletes. Developing a basic understanding of financial concepts is especially important for NCAA Division I athletes since some may pursue careers in professional sports (Renzo, 2010).

Service commitment promotes the importance of engaging with the community. Prior research indicates that community service is mandated for studentathletes by coaches and athletic departments to express their gratitude to the local community (Chalk, 2008). The results of a recent study, however, indicated a discrepancy between student-athletes' social values and actual community service engagement (Gayles et al., 2012). High-profile student-athletes were found to be the least involved in community service activities and student-athletes were generally less involved than the general student population. Differences in social values and community service engagement among student-athletes may be the result of the mission and leadership of the academic institution (Andrassy \& Bruening, 2011). 
While CHAMPS/Life Skills programming has been in existence for more than 15 years, it is an evolving program that fits the needs of student-athletes as they progress through their college experience. CHAMPS/Life Skills programming combines educational development with providing student-athletes opportunities to develop life skills. The success of these programs largely depends on athletic departments abilities to mobilize internal and external resources.

\section{Organizational Capacity}

Research related to human resources capacity in intercollegiate sport is predominantly focused on the hiring and engagement of women and gender role stereotyping (e.g., Acosta \& Carpenter, 2010; Burton, Barr, Fink, \& Bruening, 2009; Peachey \& Burton, 2011; Tiell, Dixon, \& Lin, 2012). The recruitment and retention of racial minorities, primarily in coaching positions has also been examined (e.g., Sagas \& Cunningham, 2004) as well as work-family balance among staff members (e.g., Bruening \& Dixon, 2008). Research on financial capacity, however, remains scarce. Fulks (2013) systematically analyzed revenues and expenses of NCAA Division I athletic departments from 2004 to 2012 and found only 23 FBS programs reported a net profit during the 2012 fiscal year. Nonetheless, the results indicated ticket sales, donations, and NCAA/Conference distributions are the three largest revenue sources. Previous literature on relationship and network capacity has focused on the athletic department-university relationship (Buer, 2009; Nite, Singer, \& Cunningham, 2013) and stakeholder management and perceptions in intercollegiate athletics (e.g., Putler \& Wolfe, 1999). Trail and Chelladurai (2000) found external stakeholders of an intercollegiate athletic department consistently rated development-related goals and processes higher than performance-related goals and processes. Intercollegiate athletics, however, is complicated by competing values between performance and development goals (Baxter, Margavio, \& Lambert, 1996; Buer, 2009; Cunningham \& Rivera, 2001; Wolfe, Hoeber, \& Babiak, 2002).

Research on the remaining two subdimensions of structural capacity remains scarce. Research on infrastructure and process capacity in intercollegiate athletics is limited to studies on distributive justice of resources (Hums \& Chelladurai, 1994; Kim \& Andrew, 2013; Patrick, Mahony, \& Petrosky, 2008) and Singer and Cunningham's (2012) case study of the diversity culture within an athletic department. Planning and development capacity has received even less attention and remains largely unexplored, with the exception of the work of Cunningham's work (2002; 2012). In the current study, we contribute to this gap in existing literature by providing insight into the human resources, financial, and structural capacities of intercollegiate athletic departments for student-athlete development programs. The findings contribute to our understanding of all three subdimensions of the structural capacity: (a) relationships and network, (b) infrastructure and process, and (c) planning and development.

\section{Method}

Community service is one aspect of student-athlete development that can often require significant financial and nonfinancial (i.e., human) resources to support. Andrassy and Bruening (2011) found that intercollegiate athletic departments 
varied in "dedication" to service. The authors' web-based analysis of mission statements and websites categorized the level of commitment to service among intercollegiate athletic departments. Andrassy and Bruening (2011) analyzed the athletic department mission statements from 70 institutions across the (then) Pacific-10, Western Athletic Conference, Metro Atlantic Athletic Conference, Mid-American Conference, Big East, Ivy League, and Atlantic 10 Conference. Of the 70 schools, 21 both mentioned service in their athletic department mission statement and demonstrated a dedication to service. Dedicated to service entailed the athletic department providing evidence of at least six opportunities for studentathlete community engagement each year and/or providing records of community service hours, community members reached, or the number of students involved in service (Andrassy \& Bruening, 2011). Further investigation into how intercollegiate athletic departments capitalize on their resources in approaching not only service, but student-athlete development in general, was warranted and suggested by the authors. Thus, the current study builds on the work of Andrassy and Bruening (2011) by exploring both common and unique characteristics of athletic departments, or "best practices." By helping to address a gap in the existing literature, the current study explores organizational dimensions needed for creating and sustaining a quality student-athlete development program.

\section{Data Collection}

Of the 21 institutions from Andrassy and Bruening (2011), 9 were identified for a qualitative follow-up study. Institutions were selected to represent a diversity of conferences, geographic locations, size of schools (small > 10,000; medium >20,000; large 20,000+), and a mix of both public and religiously affiliated, given the findings of Andrassy and Bruening (2011) related to the inherent service-orientations of religiously-affiliated schools. One member of the research team conducted indepth phone interviews with the CHAMPS/Life Skills Coordinator at each school during the summer of 2008. The interviews were semistructured and the interviews grounded in student involvement theory (Astin; 1984, 1993, 1999; e.g., Why were these programs introduced? Was the goal to solve a particular problem or was the life skills program introduced as part of a greater mission?) and organizational capacity theory (Hall et al., 2003) (e.g., In terms of intangible support, what are the greatest challenges you face in implementing life skills programs?). Interviews lasted from 30-60 min and were digitally recorded then transcribed verbatim by the researchers. All names and identifying information were changed to protect the confidentiality of the participants (See Table 1).

\section{Data Analysis}

Two of the researchers coded the data utilizing a priori themes based in both student involvement and organizational capacity theories (See Table 2). The researchers independently coded, utilizing NVIVO 10, one transcript then met to compare codes. Following discussion on the conceptualization of the a priori themes and subthemes, the researchers agreed on the coding for the first transcript. Then each coded a second transcript independently. The researchers again met finding that their coding was more closely aligned than it had been with the first transcript. When 
Table 1 Institutions Selected for Interviews

\begin{tabular}{llll}
\hline Pseudonym & Location & Enrollment Size & Public/Private \\
\hline Big State University & Midwest & Large & Public \\
Lake College & East & Small & Private \\
Local University & Midwest & Large & Public \\
Metro University & Midwest & Medium & Private \\
Midwestern University & Midwest & Large & Public \\
Mountain University & West & Large & Public \\
National University & Midwest & Medium & Private \\
St. Josephine's College & East & Small & Private \\
West Coast College & West & Medium & Private \\
\hline
\end{tabular}

disagreements arose as to how segments of data should be coded, they discussed the data until consensus was reached on the appropriate code. Frequently the researchers coded data to multiple themes, recognizing they belonged to more than one (Glesne, 2011). The researchers also elected to add subthemes that emerged from the data including informal evaluation, exit interviews, internal athletic department funds, and donors. The two researchers then independently coded the remaining seven transcripts, meeting again when finished to discuss codes. Upon reaching agreement, the final coding structure was solidified. The last step of data analysis was selective coding, where quotations from the data were selected that represented the themes and subthemes (Strauss \& Corbin, 1990). All school and life skill coordinator names were replaced with pseudonyms, as well as any other references that were deemed to potentially compromise the confidentiality of the participants.

\section{Results}

The data are presented according to the a priori themes established in the analysis process. Themes connected Human Resources, with subthemes Administrators, Coaches, and Student-Athletes are shared first. Next come themes related to Financial Resources including NCAA Grants, Corporate, Internal Athletic Department Funds, and Donors. And lastly, Structural Resources are shared including Relationships and Networks with subthemes Campus Partnerships and Community Partnerships; Infrastructure and Process with subthemes Academic Courses, Leadership Development, Participative Decision Making, Internal Communication, Organizational Culture, Mission-Athletic Department and Mission-University; and Planning and Development with Evaluation subthemes Alumni Feedback, Focus Groups, Informal, Surveys, and Exit Interviews.

\section{Human Resources}

Administrators. All nine life skills coordinators commented on the value of staff involvement as a human resource. Local University appreciated the moral 


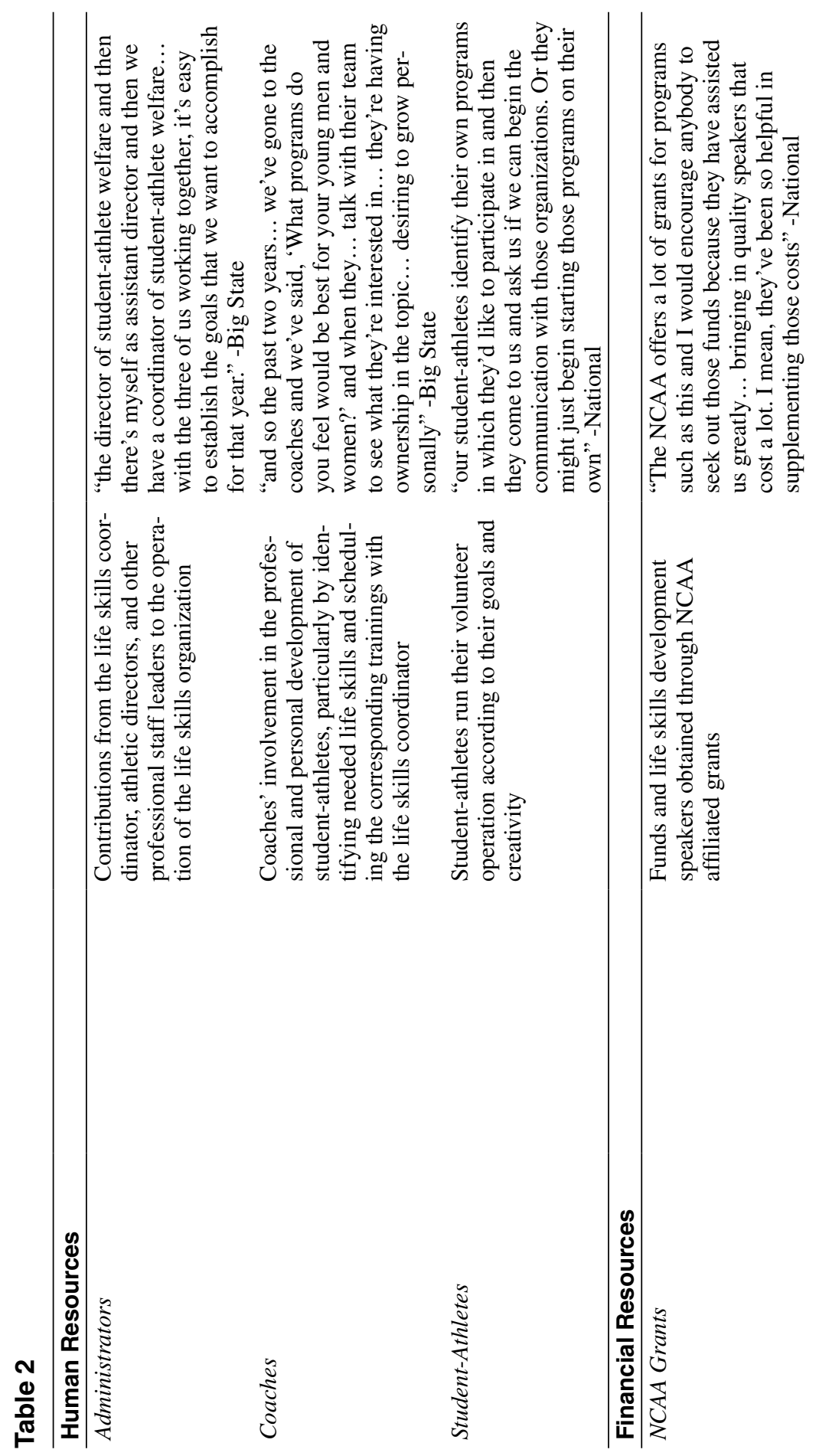



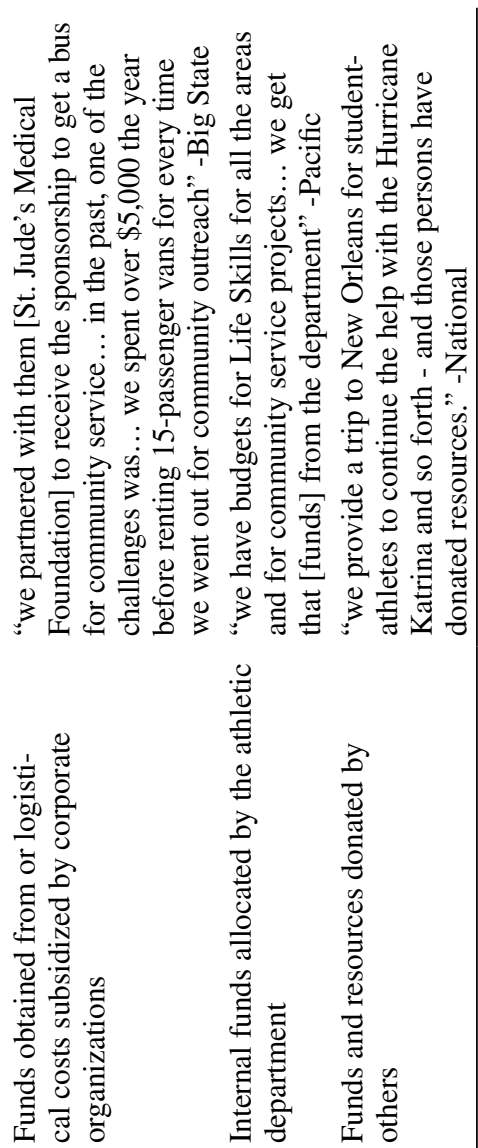

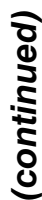

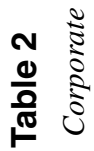
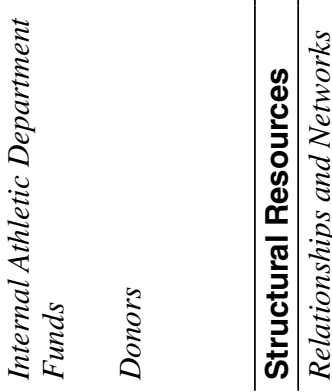

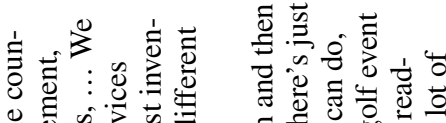

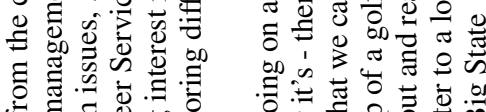

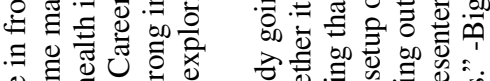
ט. ป స

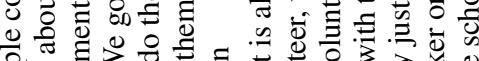

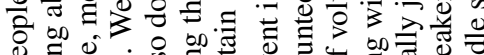

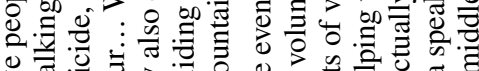

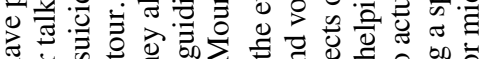
छ

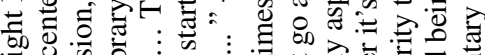

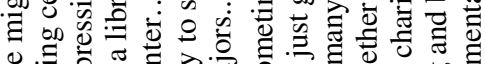

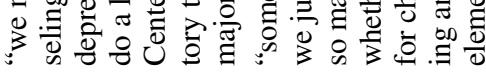

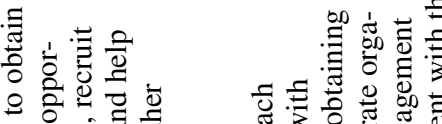
Uै

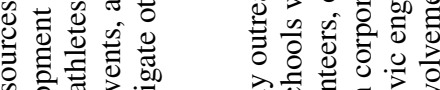

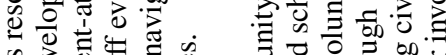

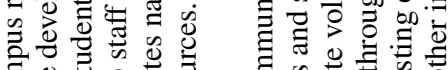

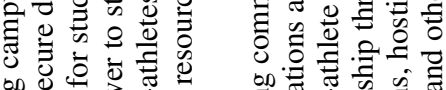
of 0

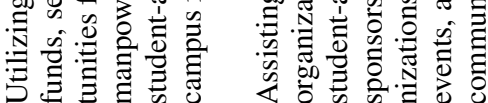

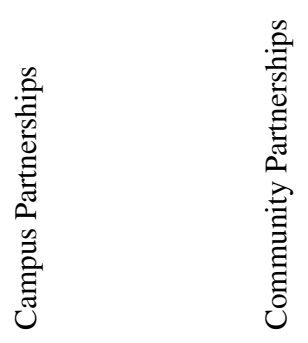

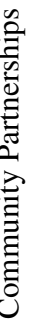




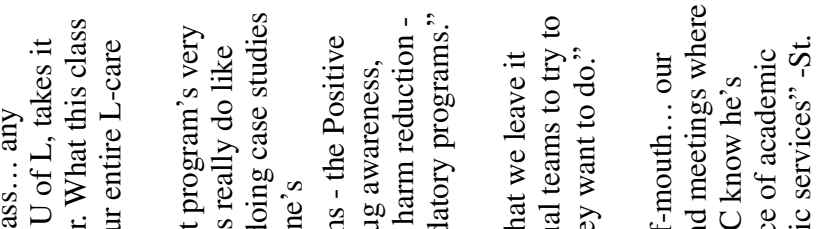

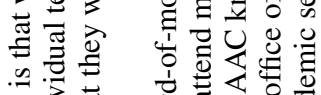

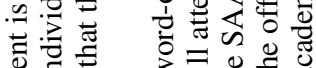

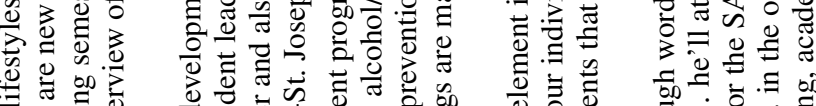

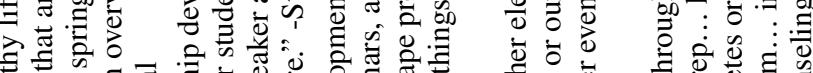

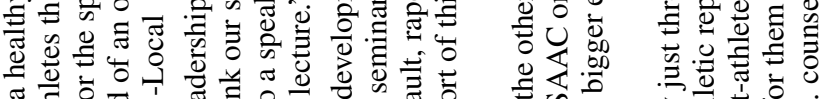

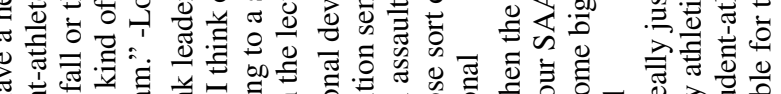

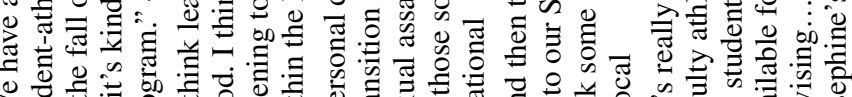

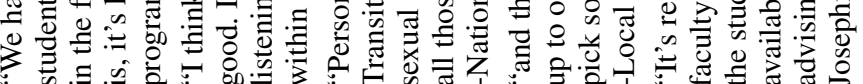

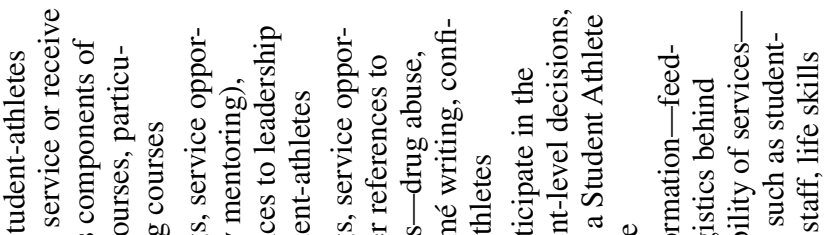

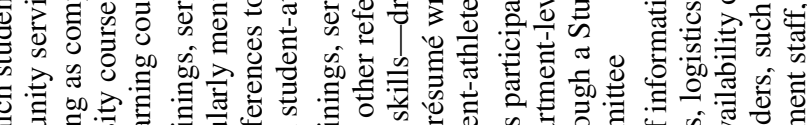

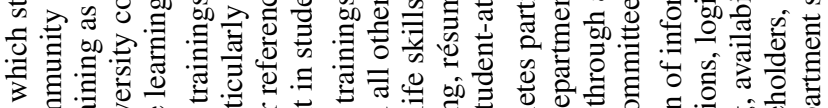

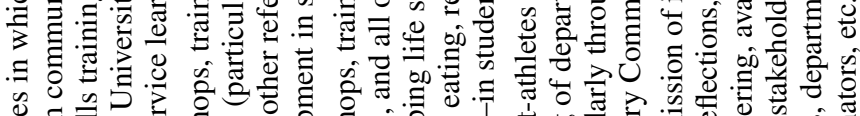

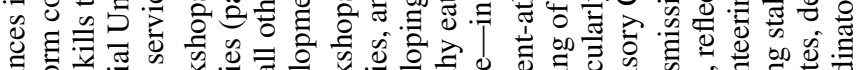

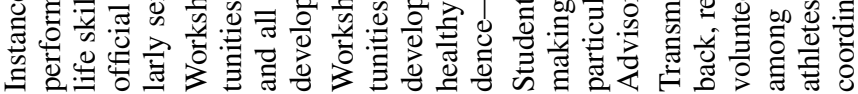

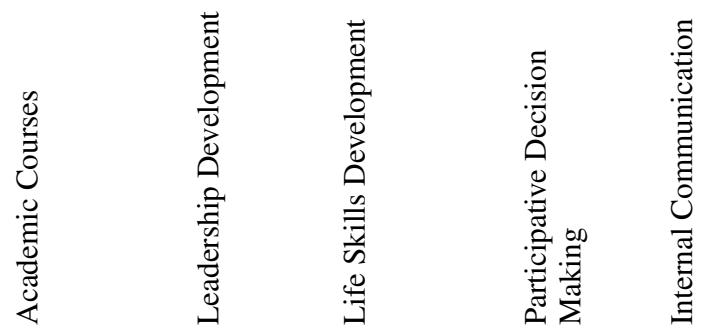

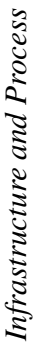



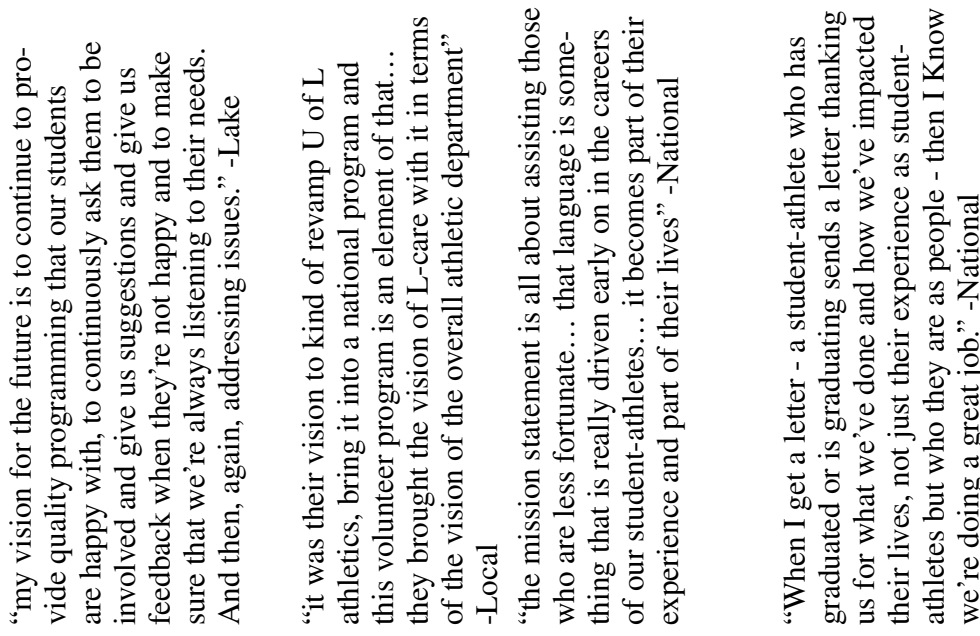

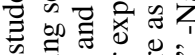

๘

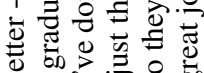

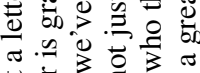

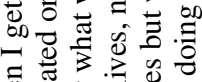

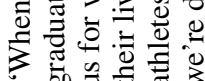

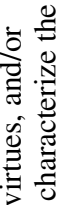

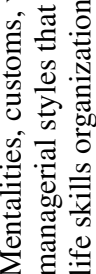
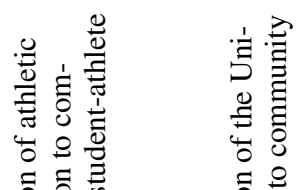

드응 호

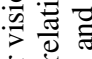

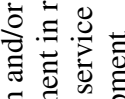

을 ڤ을

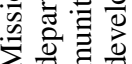

官

言宓造

光

3

胥

.

츨

岂

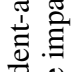

总 $\frac{0}{7}$

苞

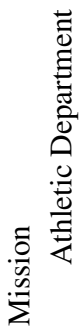

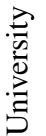

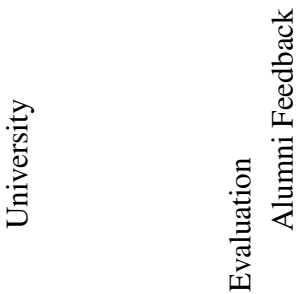

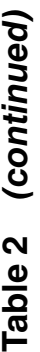

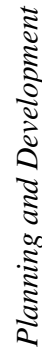

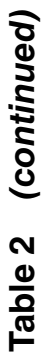




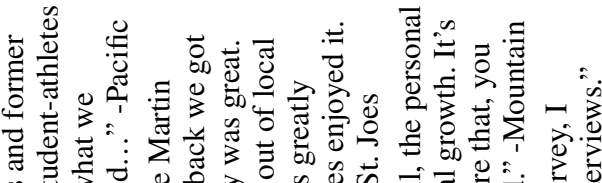

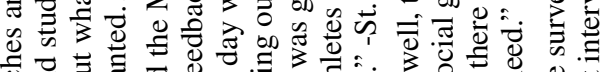

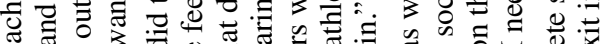
西 000 o

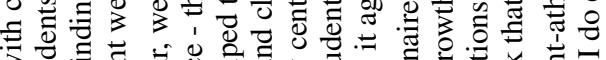

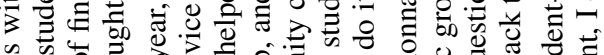

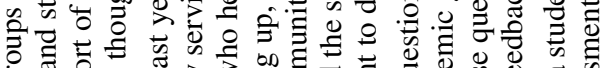

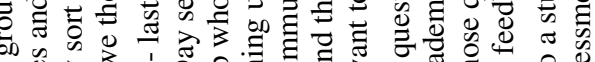

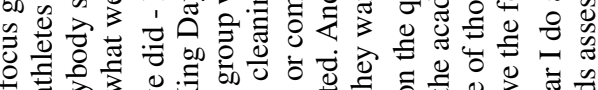

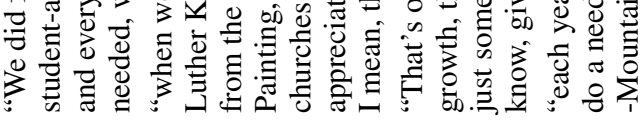

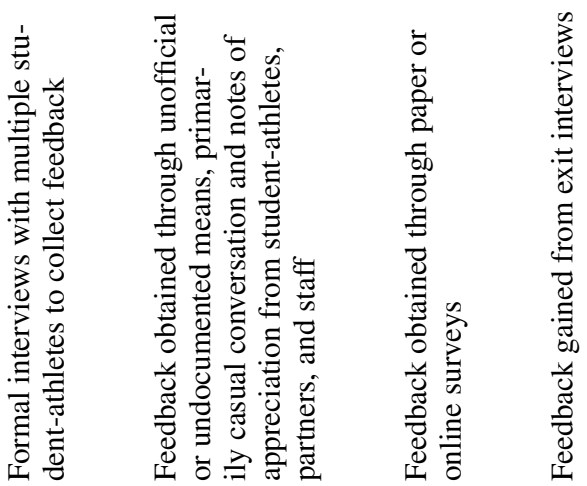

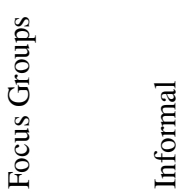

: 
support of various staff members in operating the life skills coordinator position; "we do have the backing of our administration, so the athletic director's behind us, Julie's [SWA] behind us, our SIDs [Sport Information Director] are. So we do have a lot of support and resources from our end."

Several coordinators identified lack of time as the principal challenge in addressing their many responsibilities on campus; "I supervise three other sports... oversee academic advising... strength and conditioning sports medicine. I' $m$ an advisor for the SAAC [Student-Athlete Advisor Committee]..." (Mountain University).

Coaches. Six life skills coordinators spoke to the role of coaches in promoting or not making a priority out of development opportunities for their student-athletes:

We get the information from the coaches and our coaches are really good about making sure that their kids are where they are supposed to be. (Lake College)

“. . . the coaches involved . . . in selecting what we're offering - I think that ensures the buy-in. (Big State University)

I think another challenge is kind of getting the teams involved. You know, we have a set of teams that are great, the coaches are behind it. They'll always be ready to participate and we never get pushback from them in any of our programs. And then we have other coaches who I don't think buy into it as much. We've never had actively, you know, disapprove any of our programs. But, I think in any athletic department, you know, you have the teams that are really in attendance to everything, you never have problems with them and sometimes it's harder to get buy-ins from some of the other coaches. (Local University)

The coordinators clearly stated that coaches can play a significant role in the attendance at programs, with improvements being seen when coaches were asked to be involved in the scheduling, and also how life skills activities are regarded by the student-athletes. In addition, the life skills coordinators mention how involving coaches in the process of identifying topics of interest and need for their studentathletes can be beneficial for all involved:

And with coaches, it's an opportunity - we meet with coaches - it's an opportunity for them to kind of get a better idea of where their leaders are and how their leaders think and really help them learn how to communicate with their leaders so that there isn't that gap or the misunderstandings that take place because there's a lack of communication. So we have found that this has been a tremendous asset to the student welfare and development program because leadership is always something that coaches have identified as most challenging, you know what I mean, or the reason why they haven't been successful on the field or the playing surface. (National University)

Student-Athletes. Eight coordinators identified the role of the Student-Athlete Advisory Committees (SAAC) on their campuses in providing a structure for student-athletes to become involved and develop a sense of ownership of programs and events:

So we try to ask them a lot . . .'cause we feel like if they're coming up with the ideas and can take ownership of the events a little more. (Local) 
And, the life skills coordinators know that they need to engage the SAAC member by providing guidance and encouragement:

We really encourage them to - if they're going to partner with an initiative like the literacy project that just happened in March - for them to take ownership of it. We just provide kind of the area to work. And they need to come up with the plan, come up with the committees, arrange the meetings, really run the whole event from conception all the way to completion and interact with the different areas of the university, from peers to administrators. (Metro University)

\section{Financial Resources}

NCAA Grants. Eight coordinators referred to NCAA grant monies, particularly in the context of utilizing the Speaker Grant, which Lake College, Midwestern University, and Mountain use annually. The Choices Grant, an NCAA initiative to reduce alcohol abuse on campuses (NCAA, 2014), however, was acknowledged only by Midwestern and was awarded only to Mountain.

Corporate. Four coordinators mentioned corporate financial resources during their interviews. Midwestern University recalled the past difficulty of providing community service due to the high cost of transporting student-athletes to service sites. Midwestern overcame this challenge by partnering with corporate organizations, and hoped others would use these excellent, surprisingly available resources; "there are other companies that do want to sponsor events. It's just sometimes finding the time to meet with them and to be able to showcase your program in such a light that they want to be a part."

Corporate organizations serve also as potential sources of sponsorship, particularly when "businesses or... donors have an interest in the life skills program... for example, we have [local insurance company] - they sponsor a lot of our career development events." (Local University)

Dedicated internal budgets were mentioned by seven coordinators. Metro University has access to funds from its athletic department to cover community service expenditures “depending on who's participating in [the service]." In addition to "funding that comes from athletics," Big State University "actually report[s] to the Provost's Office. So we have support both from those entities [Athletics and Provost]." Some coordinators, however, express fewer, if any resources originating from internal sources. St. Josephine's describes the supply of funds devoted to the life skills program as "very limited," while Mountain University expresses them as "not endless."

Individual donors financially support the life skills programs and leadership development opportunities at two of the participating institutions. National University sent students to New Orleans every year to assist with disaster relief, utilizing individuals' donations.

\section{Structural Resources}

Relationships and Networks. Life skills coordinators identified various types of relationships and partnerships, including those on campus and those in the community. 
All nine life skills coordinators referenced the value of campus partnerships in enhancing the capacity for service opportunities. Each spoke to the role of campus partnerships in their programs. Midwestern University described a way to tap into campus service learning courses to supplement the student-athlete volunteers at large events:

some of their [College of Education] classes, students are required to do $\mathrm{x}$ number of community service hours a semester. And so, we've been partnering with them...that's really increased our number of volunteers that we've had for our events.

Campus partnerships yield opportunities for direct service as well as opportunities to become trainers, which can lead to the development of leadership skills through teaching others:

athletes go through their [campus justice department] training program and actually go into middle schools and do some [conflict resolution] workshops (Metro University).

one to two members of each team take a class... and then those people served as mentors back to their team (Big State University).

Eight of the life skills coordinators spoke to how strong community partnerships aided in their community service efforts with student-athletes. Midwestern University acknowledged the credibility of community partners and how that encouraged student-athletes to fully appreciate advice: "When they get a chance to see someone from the outside... all the things that I've kind of been telling them come to be real." Stronger partnerships presented more opportunities for collaboration.

Community partners provided not only professional training but service volunteer opportunities. According to Local University, sustained, multiple-visit service appealed most to student-athletes: "they get to see the kids on a more consistent basis... they can see the progress and it's more fulfilling for them...they see that they're making more of an impact than they may know."

Engaging busy student-athletes in service at sites beyond the local community posed a challenge; "we want to...do as much as we can to reach out to the community... but not at the expense of the limited free time that our student-athletes have... we want to make sure we do justice to the organization" (Big State University).

Infrastructure and Process Capacity. The infrastructure and process capacity was reflected through academic course offerings, leadership development, the culture of the department, and the missions of both the athletic department and university.

Academic Courses. Six coordinators elaborated on academic courses that are connected to the service commitment of their student-athletes. College service learning courses themselves may or may not be mandatory: "some [service learning] courses... are not mandated... students don't have to do the service learning as part of their curriculum" (Lake College). And at Midwestern University: "it is a requirement for freshmen."

Local University's life skills development programs were embedded in healthy lifestyle classes that new student-athletes are enrolled in: "we use that class that all of the student-athletes have to take as kind of the way to introduce our program." 
Leadership Development. Seven schools offered official leadership trainings including "the national leadership conference" for Midwestern, "a leadership academy...we work with veteran leaders, emerging leaders...this has been a tremendous asset to the student welfare and development program" for Nation, and "career fairs" as well as speakers who "always has case studies, role playing" for St. Josephine's.

Leadership development opportunities through service typically involve mentoring. Midwestern cites "the [Helping Hands] Institute... a program that...some of our students...become mentors of these men and women who are in prison and trying to serve as a positive role model and also a friend."

Though universities provided official leadership training workshops and mentoring-service opportunities, they also cultivated leadership by extending project ownership and decision-making to student-athletes, teams, and SAACs: "the other element [of leadership opportunities] is that we leave it up to our SAAC or our individual teams to try to pick some bigger events" (Local University).

Seven schools commented on the life skills programming that is available to their student-athletes. Lake College capitalizes on the recentness of events to engage students in relevant life skills, "if we have a certain issue going on campus, you know, we would look to find a speaker to come and talk about that particular issue because that's current... when there are issues, use those issues as opportunities to educate on those issues as we go along." Though not exactly current events, Mountain University expresses a similar attention to current needs of studentathletes by developing a program "that fits their needs" based on annual an annual student-athlete evaluation and exit interview.

Similar to Lake College, universities favor inviting outside speakers as their primary mode of developing student-athletes' life skills. These speakers and topics are selected to "make our program a little more well-rounded" (Lake College). Local attempts to "rotate it [speakers] so that we're not repeating the same information... we try to keep tabs kind of on a three-to-four year cycle, so that the kids will be hearing the information at least once while they're here." To prevent topic stagnation, Midwestern University incorporates a diversity of development themes including "financial management, nutrition, etiquette, networking, alcohol education, sexual violence prevention." West Coast University also demonstrates life skill topic breadth through hosting workshops on "strength and conditioning," "supplements," "mental health and...managing the competitiveness and the stress of competition."

Some life skill topics, however, persist each year. Mountain University finds "sometimes, though, that there's always needs in education about mental health and depression, suicide - those different personal areas. So some stay the same."

West Coast University takes advantage of how they have "more resources and programming in so many different ways - from departments to their residential education" to help student-athletes successfully apply to graduate schools. "We bring in admissions officers from our business school, med school, law school to talk about trends, what people are looking for on applications...they feel like they're getting a real front-row seat for that."

Three coordinators discussed the role of participative decision making. Not unlike what is positive about having coaches involved in decisions around life skills programs, data provide insight into how involving the student-athletes in determining topics and times can also prove positive: 
So, we just try to listen to our kids and bring in things that are current and obviously address things that are problems. (Lake College)

And so the past two years, what we've done is we've gone to the coaches [they] talk with their team to see what they're interested in. They come with a new kind of excitement for learning this topic and learning more about it instead of 'oh, we were forced to go to this' ... . asking them what they want instead of just saying here are a bunch of options, just choose. (Midwestern University)

Internal Communication. Each of the nine athletic departments had its own system of communicating with its staff and student-athletes. All used e-mail extensively and relied on "word of mouth" among athletes and coaches to publicize upcoming student development events and help drive attendance at the events. However, the departments with the most extensive and effective internal communication had multiple means of communication:

Our SAAC (Student Athlete Advisory Committee) meets once a month and will provide information - flyers - that they can take back, or sign-up sheets for service opportunities. We also send out a weekly [school nickname] Life Skills e-letter to all of the coaches, staff, student-athletes and we'll send updates through our Life Skills e-mail address. We post flyers throughout our building. We have a plasma screen here in the building that will publicize different opportunities whether it's a workshop or community service activities.... And then on our website, we will put pictures up of our student-athletes going out and doing different things. And we also have a picture board in our building, so we update on a regular basis. So when our student-athletes go out on community service events, we'll take photos and bring them back. It was kind of amazing to me how much the student-athletes will check that and see who from their team has been involved in it. So, they pay closer attention to that than I ever might have thought they would. (Big State University)

These departments also depended heavily on student-athletes having online access to information, which often required additional staff:

A lot of resources that we have for our student-athletes are online...we have an intern that's working with us from [local Division III college].... She has done a great job assessing our career resources...then also helping us get a lot of information online. (Midwestern University)

Organizational Culture. Organizational culture encompassed many aspects of the infrastructure of athletic departments related to the operation of student-athlete development programs. As such, all nine coordinators discussed organizational culture.

Each life skills coordinator discussed how the importance of student-athlete development became ingrained in the culture of their departments by the breadth of programming offered as well as by which sessions are made mandatory. Clearly the departments want to increase student athlete involvement but also provide for choice on what to attend and how often: "we usually have as many as three speakers a semester and...usually, it's the bigger subjects, like drug and alcohol...that we 
make mandatory (Lake College). And, given that each of the institutions was identified based on their high commitment to service, expectations for student-athletes to participate are also high although not mandated at all of the schools: "coaches do ask their students to do things...the students don't really argue if their coach says 'we're doing Habitat for Humanity on Saturday.' They just say 'OK, we're doing that,' but the coaches are expected to give their students... volunteer and community outreach opportunities" (National). Clearly the expectation to be involved in all student development activities and events was high at each institution.

Competition and ritual was also strongly embedded in the CHAMPS/Life Skills programs. Contests for highest rates of participation, awards for community service, and recognition of teams and individuals through campus communication channels were all mentioned by the life skills coordinators;

Spirit points, we give them for attending other athletes'... sports. Like showing up and cheering basically. And you sign in. And you get points for percentage of your team that attends another team's event. You get them for percentage of your team doing community service, percentage of your team above whatever the [conference] GPA is. (Metro University)

And lastly, a balance of leadership was important at all of the schools: "So some of it is top-down and some of it is bottom-up" (Metro University). The West Coast University coordinator reinforced that approach:

To sort of centralize everything, that gives you the strength of communication, numbers, buy-in from people that there's a more clear and consistent message. But on the same hand, I'd like to brand something very independent for Life Skills...that the students [own] and understand year after year after year.

Mission-Athletic Department. Each of the life skills coordinators referenced working to follow the charge laid out by the NCAA within their athletic department's mission. While each department had its own mission, it was common that sense departments fell under the auspices of the NCAA, their missions also reflected the goals established around student-athlete development through the NCAA's CHAMPS/Life Skills program. But a select group of the athletic departments had also made it part of their mission to be the best at what they do, to be model student-athlete development programs. And, unlike those who only stated this aspect of their mission, these schools were actually creating and sustaining a model:

We would like to make [name of program]... a competitive advantage with our student-athletes...when we're out recruiting...we've spent a lot of time working on it and we're finding we do think it's one of the best in the country. So, our vision is to continue it to be cutting-edge ...to continue to be a leader in this area, to set an example and to continue to push ourselves and push our boundaries. (Local University)

One of the religiously affiliated schools, also striving to be a model studentathlete development program, explained the importance of aligning the athletic department and university missions: 
And I think what makes it unique here at [school name] is it directly links up with the core values of the university...the mission statement is all about assisting those who are less fortunate. And so that language is something that is really driven early on in the careers of our student-athletes and our students... it becomes part of their experience and part of their lives...academic excellence, athletic success, personal/professional development, and community involvement. (National University)

Mission-University. The life skills coordinators at the four religiously affiliated schools referred to alignment between athletic department mission statements specifically mentioning Life Skills, service in particular, and the overall university mission. For instance, the coordinator at Lake College stated:

Because we are a [religious affiliation] school...[it's] part of the college admission in general, they offer a lot of opportunities for students to do leadership... and volunteer work... a lot of students have chosen to come here for that reason... and they know that's part of the mission right from the beginning.

Metro University and St. Josephine's College also referred to their university's "greater mission" (Metro) and their Life Skills program goals being defined "through the university mission statement" (St. Josephine's).

\section{Planning and Development}

Evaluation. References to alumni feedback were made by four of the life skills coordinators. They valued the time and the opinions of alumni in helping improve their programs and the experiences of the current student-athletes. Big State University used alumni in a yearly career and networking night:

We bring back former [student-athletes] to speak...about their careers. And one of the best things at that event is where the former student-athletes tell us how valuable it is. Once they get out and they've left the program, they can be very honest and I think they have a better idea of how beneficial our programming was.

In addition, Big State University's coordinator commented that:

Former student-athletes who were here prior to the Life Skills Program.... and to hear from them that they wish they would have had the opportunity to go through [the] programming that we offer...tells us also that what we're doing is pretty valuable.

Midwestern University ran a formal program for student-athletes transitioning from college into the workforce and made use of alumni involvement as well:

We also bring back former student-athletes to be a part of this group to provide support...hearing what some of...the former student-athletes say...it's really helping our current student-athletes to figure out what things they need to be doing to prepare. 
Focus Groups. Four coordinators elaborated on the focus groups that they had conducted with current student-athletes to assess receptivity to the life skills programs. (Big State University) met with student-athletes multiple times per year to gauge opinions and gather suggestions. Midwestern University specifically directed a focus group on community service facilitated by the student intern in the Life Skills Office, not the staff, to create an open environment for the studentathletes who "really want to do [service] . . and [that] allowed us to have some good feedback on how we could improve our program." In particular, Midwestern learned about how the timing of programs made it difficult for student-athletes to participate and that they preferred sports-related service events, especially with youth and on campus.

West Coast University also conducted focus groups with coaches that addressed questions around life skills programming "being mandatory and not mandatory, investigating a menu-option kind of program, and giving people [opportunities to share their opinions]." The findings supported the programming that was being offered and the way in which it was being offered, but did identify attendance as an issue. Conducting focus groups allowed for West Coast University coaches and life skills staff to come together to formulate strategies to address attendance.

Each school referenced the use of informal data gathering as a means to inform programming. These segments included examples of conversations between staff, coaches and students as Midwestern's coordinator shared, "I see students on a daily basis and we're always trying to connect with them and get to know them on a personal level so we can find out how we can better our programs." Also, unsolicited emails from coaches and students (current and former) have been informative:

We even have students who have transferred to other schools e-mail us and say.... "At my school they had this person come and he was really good. It might be a great opportunity." That actually happened this year. We had. . . an alcohol and drug presentation. . . a former student of ours who had transferred had seen him at his new school. And he wrote to his coach and said, 'This was awesome. Maybe if I had heard him speak when I was at [Lake College], I might have been able to do better.' So we brought the guy in. (Lake College)

All but one of the schools regularly made use of survey data in their evaluations. Lake College's coordinator stated, "We don't actually do any like surveys at the end of programs. And maybe that's something [we] should think about doing." [Big State University] was "constantly evaluating every program we do, the students and coaches have the opportunity to fill out an evaluation. It's not real long ...but allows the staff to gather valuable information on student-athlete and coach opinions." In addition to evaluating individual events and programs, schools also administered evaluations at the end of each academic year. Local University asked student-athletes "about their experience, or quality of experience ...which [community service opportunities] they enjoyed, which they didn't and why, suggestions, that kind of stuff."

Each school also referenced completing the NCAA Life Skills evaluation forms for programs and then using that data internally as well. Some of the larger institutions that had access to offices specializing in measurement and evaluation also made use of those services: 
We also have an online assessment that we worked with our [measurement and evaluation office] and they provided us a great tool to be able to cover all of our five commitment areas of the CHAMPS/Life Skills program and be able to send this link out and have students respond. (Midwestern University)

Five life skills coordinators referenced performing exit interviews with studentathletes as a standard means of evaluation and they outlined how valuable these data can be to informing future programming: "I think one of the best things... every campus has their student-athletes go through an exit interview when they're leaving as seniors...that information is always very helpful" (Big State University). Metro's coordinator felt that the timing of these interviews was wise because "in the end, like on reflection, they see that they got a lot out of it. During it, they're probably a little bit caught up in the moment." But the life skills coordinators also emphasized the amount of time and energy needed to ensure that the exit interviews occurred and that the data gathered was put to good use: it's "hard to do .... and I don't do a real good job with that. I have to admit. I probably should do more of evaluation and follow-up than I do" (Mountain University).

\section{Discussion}

Based on the previous work of Andrassy and Bruening (2011), we conducted in-depth interviews with the life skills coordinators of 9 of 21 institutions identified as being "dedicated" to service. Given the challenging nature of engaging student-athletes in community service, namely their schedules, these institutions had clearly found methods to work with the challenges. The schools represented a diversity of conferences, sizes, geographic locations, and were both public and private institutions. The current investigation focused on identifying how the level of student-athlete involvement (Astin 1984, 1993, 1999; Astin \& Sax, 1998) depends on the extent to which the athletic department mobilizes its organization capacity (i.e., existing assets and resources for providing opportunities and promoting student involvement) (Hall, et al., 2003). And, as a result of service being one portion of CHAMPS/Life Skills programming, we expanded our investigation, and the work of previous research to include all aspects of this student development program.

Human resource mobilization through the athletic director, department staff, and coaches was a common strength across the institutions (Hall, et al., 2003; Misener \& Doherty, 2009). But, we would be remiss if we did not note some human resource challenges (e.g., lack of time) with the coaches, students, and staff. Coaches appear to have played an integral part in the engagement of student-athletes in community service and their perceived importance of life skills activities too. When coaches were seen as part of the equation, student-athletes were more likely to be involved. A related finding was the role of coaches in identifying meaningful opportunities for their student-athletes. Coaches who took this responsibility as a chance to enhance communication with and develop leadership among their athletes reaped the greatest benefits (Jarvie \& Paule-Koba, 2012).

And while coaches had an important role at the institutions, life skills coordinators also indicated the importance of the student-athlete voice. The coordinators had strong beliefs about the student-athlete ownership and regularly asked them 
for their ideas and opinions to involve them in the planning for service activities and life skills events. By being part of the process, student-athletes then played a larger role in the implementation. This finding clearly supported Astin's work (1984, 1993, 1999; Astin \& Sax, 1998) and demonstrated a crucial piece of the link between student involvement and maximizing organizational capacity.

Overall, we found relatively strong human resource capacity among all nine athletic departments.

The results indicated the importance of participatory decision-making among internal stakeholders and development of shared values regarding student-athlete development. Similar to the findings of research on capacity of community sport clubs (Doherty, Misener, \& Cuskelly, in press; Misener \& Doherty, 2009), mutual values were an imperative component of the human resource capacity of 'dedicated' athletic departments.

On the other hand, student-athlete development efforts were limited by a department's financial capacity. Considering the lack of profitable athletic departments (Fulks, 2013), staff members had employed creative strategies to secure sufficient funding for their programming (e.g., grants, corporate partners, internal funds). Only a few of the institutions had been able to make effective use of corporate partners and donors as developing those kinds of relationships take time that many of the life skills coordinators indicated was not in abundant supply. Most of the coordinators did, however, use funds made available to them internally within their departments as well as through NCAA grant programs.

Wicker, Vos, Scheerder, and Breuer (2013) along with Misener and Doherty (2013) discovered resource scarcity often served as a determinant of formation of external partnerships among nonprofit sport organizations. Similarly, we found campus and community partnerships were important strategies for overcoming limited resources and increasing capacity to engage student-athletes in life skills development. The relatively high prevalence of campus partnerships indicated that life skills coordinators and their departments were leveraging existing resources within their institutions and communities.

The life skills coordinators identified the importance of clear and frequent internal communication through multiple channels, supporting the critical role of communication processes within sport organizations (Doherty et al., in press). To disseminate information to student-athletes and coaches about potential service opportunities and student development events, coordinators needed to engage these internal channels and even create their own. Departments with the most sophisticated internal communication systems and processes often reported having additional staff to manage these initiatives. Thus, human resources capacity was imperative for other aspects of organizational capacity (Hall et al., 2003).

All of the institutions reported high expectations of involvement in CHAMPS/ Life Skills events. As such, a culture embracing the importance of student-athlete development was one of the most influential findings of the study. The internal recognition of service engagement and life skills activity participation also emerged in support of the prodevelopment culture. Coordinators reported that student-athletes stood to gain academically, in their sense of civic responsibility, in community service, as leaders, and in life skills development. Evidently, leaders of athletic departments dedicated to service appear to instill cultures valuing student-athlete development and promoting practices to increase student-athlete engagement. These 
results support that an organizational culture provides an institutional framework for internal stakeholders to take action (Chen, Lune, \& Queen, 2013).

Supporting previous work (Andrassy \& Bruening, 2011), the public institutions also viewed their student development efforts as a competitive advantage within the intercollegiate sport landscape. Their commitment to student-athlete development was documented in their athletic department mission. Likewise, the private institutions stressed importance of university and athletic mission alignment.

The athletic departments in the study also engaged in formal and informal planning efforts to advance their student development programs including the use of alumni surveys, focus groups and surveys with current student-athletes, and senior exit interviews. In addition, coordinators used NCAA data for internal planning and evaluation.

In sum, findings indicate these 'dedicated' athletic departments are characterized by strong organizational capacity for engaging student-athletes in meaningful service efforts. The critical role of coaches and mutual values among internal stakeholders emerged as the primary strengths of department's human resources capacity. Despite the limited financial capacity, departments were able to creatively secure some funding for development programs. The ability to leverage external relationships, an organizational culture promoting participative decision-making and student-athlete development, and on-going efforts to improve service and life skills opportunities for student-athletes indicated strong structural capacity.

\section{Implications and Future Research}

Astin's Student Involvement Theory (1984, 1993, 1999; Astin \& Sax, 1998) suggests the importance of active participation of students in their college experience for improved academic and life skills development, in addition to the institution (i.e., the athletic department) providing a supplementary role connecting students with activities to augment their development. While Astin's formulation of Student Involvement Theory focused only on students in the general higher education context, we extended the theory to student-athletes. Our findings, thus, contribute to the literature by examining programs designed specifically for student athletes, a demographic not adequately addressed in the existing literature (Andrassy \& Bruening, 2011).

Our primary interest was developing a better understanding of the athletic department's role promoting and increasing development opportunities for Division I student-athletes or, in other words, how, how organizational factors can be used to increase desired individual outcomes. The implications of our findings are a contextualization and better understanding of specific examples of critical capacity strengths associated with student-athlete development programs. In the end, we, and the athletic administrators interviewed, are interested in developing a better understanding of how student-athlete involvement can be increased as this involvement is directly related to improved academic and student development (Astin 1984, 1993, 1999; Astin \& Sax, 1998).

Overall, the organizational capacity of the athletic departments studied, or their ability to mobilize both internal and external resources, had tremendous impacts on their CHAMPS/Life Skills program effectiveness. However, the athletic departments demonstrated their support for CHAMPS/Life Skills with nonfinancial resources as well. A commitment to student development formed the foundation for maximizing 
capacity. As such, future research should continue to identify existing institutions that are "dedicated" to the development of their student-athletes, and institutions that are expanding their dedication, and examine how organizational capacity impacts their ability to provide programming that engages student-athletes. In addition, conducting research with the student-athletes themselves on the quality of their experiences and factors that determined that quality is necessary to complement the data from life skills coordinators.

\section{References}

Acosta, R.V., \& Carpenter, L.J. (2010). Women in intercollegiate sport: A longitudinal study-thirty three year update 1977-2010. West Brookfield, MA: Brooklyn College.

Andrassy, E.J., \& Bruening, J.E. (2011). From rhetoric to reality: NCAA division I athletic department mission statements and student-athlete community service efforts. Journal of Issues in Intercollegiate Athletics, 4, 271-288.

Astin, A.W. (1984). Student involvement: A developmental theory for higher education. Journal of College Student Personnel, 25(4), 297-308.

Astin, A.W. (1993). What matters in college? Four critical years revisited. San Francisco, CA: Jossey Bass.

Astin, A.W. (1999). Student involvement: A developmental theory for higher education. Journal of College Student Development, 40(5), 518-529.

Astin, A.W., \& Sax, L.J. (1998). How undergraduates are affected by service participation. Journal of College Student Development, 39(3), 251-263.

Baxter, V., Margavio, A.V., \& Lambert, C. (1996). Competition, legitimation, and the regulation of intercollegiate athletics. Sociology of Sport Journal, 13(1), 51-64.

Benford, R.D. (2007). The college sports reform movement: Reframing the "edutainment" industry. The Sociological Quarterly, 48(1), 1-28. doi:10.1111/j.15338525.2007.00068.x

Blanchard, C.M., Amiot, C.E., Perreault, S., Vallerand, R.J., \& Provencher, P. (2009). Cohesiveness, coach's interpersonal style and psychological needs: Their effects on self-determination and athletes' subjective well-being. Psychology of Sport and Exercise, 10(5), 545-551. doi:10.1016/j.psychsport.2009.02.005

Bowen, W.G., \& Levin, S.A. (2011). Reclaiming the game: College sports and educational values. Princeton, NJ: University Press.

Bruening, J.E., \& Dixon, M.A. (2008). Situating work-family negotiations within a life course perspective: Insights on the gendered experiences of NCAA division I head coaching mothers. Sex Roles, 58(1/2), 10-23. doi:10.1007/s11199-007-9350-x

Buer, T. (2009). Organizational complexity: The athletics department and the university. New Directions for Higher Education, 148, 109-116. doi:10.1002/he.374

Burton, L.J., Barr, C.A., Fink, J.S., \& Bruening, J.E. (2009). Think athletic director, think masculine?: Examination of the gender typing of managerial subroles within athletic administration positions. Sex Roles, 61(5/6), 416-426. doi:10.1007/s11199-009-9632-6

Chalk, P.T. (2008). Motives and values associated with participation in intercollegiate student-athlete community service: Implications for athletics department leadership. (500th ed.). Tucson, AZ: The University of Arizona., Retrieved from http://search. proquest.com/docview/304684528?accountid=14665..

Chen, K.K., Lune, H., \& Queen, E.L. (2013). How values shape and are shaped by nonprofit and voluntary organizations: The current state of the field. Nonprofit and Voluntary Sector Quarterly, 42(5), 856-885. doi:10.1177/0899764013480273

Clary, E.G., Snyder, M., \& Ridge, R.D. (1992). Volunteers' motivations: A functional strategy for the recruitment, placement, and retention of volunteers. Nonprofit Management \& Leadership, 2(4), 333-350. PubMed doi:10.1002/nml.4130020403 
Cunningham, G.B. (2002). Examining the relationship among miles and snow's strategic types and measures of organizational effectiveness in NCAA division I athletic departments. International Review for the Sociology of Sport, 37(2), 159-175. doi:10.1177/1012690202037002003

Cunningham, G.B. (2012). Diversity training in intercollegiate athletics. Journal of Sport Management, 26(5), 391-403.

Cunningham, G.B., \& Rivera, C.A. (2001). Structural designs within American intercollegiate athletic departments. The International Journal of Organizational Analysis, 9(4), 369-390. doi:10.1108/eb028941

Doherty, A., Misener, K., \& Cuskelly, G. (in press).Toward a multidimensional framework of capacity in community sport clubs. Nonprofit and Voluntary Sector Quarterly.

Eisinger, P. (2002). Organizational capacity and organizational effectiveness among streetlevel food assistance programs. Nonprofit and Voluntary Sector Quarterly, 31(1), 115-130. doi:10.1177/0899764002311005

Fulks, D. (2013). Revenues \& expenses: 2004 - 2012 NCAA Division I intercollegiate athletics programs report. Indianapolis, IN: National Collegiate Athletic Association.

Gayles, J.G., \& Hu, S. (2009). The influence of student engagement and sport participation on college outcomes among Division I student athletes. The Journal of Higher Education, 80(3), 315-333. doi:10.1353/jhe.0.0051

Gayles, J.G., Rockenbach, A.B., \& Davis, H.A. (2012). Civic responsibility and the student athlete: Validating a new conceptual model. The Journal of Higher Education, 83(4), 535-557. doi:10.1353/jhe.2012.0024

Glesne, C. (2011). Becoming qualitative researchers: An introduction (4th ed.). Boston, MA: Pearson Education, Inc.

Hall, M.H., Andrukow, A., Barr, C., Brock, K., de Wit, M., \& Embuldeniya, D. (2003). The capacity to serve: A qualitative study of the challenges facing Canada's nonprofit and voluntary organizations. Toronto, ON: Canadian Centre for Philanthropy.

Hums, M.A., \& Chelladurai, P. (1994). Distributive justice in intercollegiate athletics: The views of NCAA coaches and administrators. Journal of Sport Management, 8(3), 200-217.

Jarvie, B.D., \& Paule-Koba, A.L. (2012). The perceptions and effects of community service: Participation among intercollegiate men's basketball players. Journal of Issues in Intercollegiate Athletics, 5, 283-300.

Kamusoko, S.D., \& Pemberton, C.L.A. (2011). Student-athlete wellbeing and higher education persistence. Journal of Issues in Intercollegiate Athletics, 4, 207-235.

Kamusoko, S.D., \& Pemberton, C.L.A. (2013). Student-athlete wellbeing and persistence: An in- depth look at student-athlete perceptions. Journal for the Study of Sports \& Athletes in Education, 7(1), 41-61. doi:10.1179/1935739713Z.0000000003

Kim, S., \& Andrew, D.P. (2013). Organizational justice in intercollegiate athletics: Perceptions of coaches. Sport Management Review, 16(2), 200-210. doi:10.1016/j. smr.2012.08.001

Kuh, G.D. (2001). Assessing what really matters to student learning: Inside the national survey of student engagement. Change, 33(3), 10-17. doi:10.1080/00091380109601795

Kuh, G.D., Cruce, T.M., Shoup, R., Kinzie, J., \& Gonyea, R.M. (2008). Unmasking the effects of student engagement on first-year college grades and persistence. The Journal of Higher Education, 79(5), 540-563. doi:10.1353/jhe.0.0019

Lafrenière, M.A.K., Jowett, S., Vallerand, R.J., \& Carbonneau, N. (2011). Passion for coaching and the quality of the coach-athlete relationship: The mediating role of coaching behaviors. Psychology of Sport and Exercise, 12(2), 144-152. doi:10.1016/j. psychsport.2010.08.002

Misener, K., \& Doherty, A. (2009). A case study of organizational capacity in nonprofit community sport. Journal of Sport Management, 23(4), 457-482. 
Misener, K., \& Doherty, A. (2013). Understanding capacity through the processes and outcomes of interorganizational relationships in nonprofit community sport organizations. Sport Management Review, 16(2), 135-147. doi:10.1016/j.smr.2012.07.003

Murphy, G.M., Petitpas, A.J., \& Brewer, B.W. (1996). Identity foreclosure, athletic identity, and career maturity in intercollegiate athletes. The Sport Psychologist, 10(3), 239-246.

NCAA. (2007). NCAA CHAMPS/Life Skills Program. Retrieved from http://www.ncaapublications.com/productdownloads/LS07.pdf

NCAA. (2014), NCAA Choices Grant Program. Retrieved from http://www.ncaa.org/healthand- safety/policy/ncaa-choices-grants

Nite, C. (2012). Challenges for supporting student-athlete development: Perspectives from an NCAA division II athletic department. Journal of Issues in Intercollegiate Athletics, 5, 1-14.

Nite, C., Singer, J.N., \& Cunningham, G.B. (2013). Addressing competing logics between the mission of a religious university and the demands of intercollegiate athletics. Sport Management Review, 16(4), 465-476. doi:10.1016/j.smr.2013.03.002

Pascarella, E.T., \& Terenzini, P.T. (1991). How college affects students: Findings and insights from twenty years of research. San Francisco, CA: Jossey-Bass.

Pascarella, E.T., \& Terenzini, P.T. (2005). (Vol. 2. How college affects students: A third decade of research. San Francisco, CA: Jossey-Bass.

Patrick, I.S.C., Mahony, D.F., \& Petrosko, J.M. (2008). Distributive justice in intercollegiate athletics: Perceptions of equality, revenue production, and need. Journal of Sport Management, 22(2), 165-183.

Peachey, J.W., \& Burton, L.J. (2011). Male or female athletic director? Exploring perceptions of leader effectiveness and a (potential) female leadership advantage with intercollegiate athletic directors. Sex Roles, 64(5/6), 416-425. doi:10.1007/s11199-010-9915-y

Peterson, N.A., \& Zimmerman, M.A. (2004). Beyond the individual: Toward a nomological network of organizational empowerment. American Journal of Community Psychology, 34(1/2), 129-145. PubMed doi:10.1023/B:AJCP.0000040151.77047.58

Putler, D.S., \& Wolfe, R.A. (1999). Perceptions of intercollegiate athletic programs: Priorities and tradeoffs. Sociology of Sport Journal, 16(4), 301-325.

Renzo, B.F. (2010). Hall offame: How to manage financial success as a professional athlete. Bloomington, IN: iUniverse Publishers.

Richard, S., \& Aries, E. (1999). The division III student-athlete: Academic performance, campus involvement and growth. Journal of College Student Development, 40(3), 211-218.

Sagas, M., \& Cunningham, G.B. (2004). Does having "the right stuff" matter? Gender differences in the determinants of career success among intercollegiate athletic administrators. Sex Roles, 50(5/6), 411-421. doi:10.1023/B:SERS.0000018895.68011.fa

Shulman, J.L., \& Bowen, W.G. (2001). The game of life: College sports and educational values. Princeton, NJ: Princeton University.

Singer, J.N., \& Cunningham, G.B. (2012). A case study of the diversity culture of an American university athletic department: perceptions of senior level administrators. Sport Education and Society, 17(5), 647-669. doi:10.1080/13573322.2011.552572

Strauss, A., \& Corbin, J. (1990). Basics of qualitative research: Techniques and procedures for developing grounded theory (2nd ed.). Newbury Park, CA: Sage.

Tiell, B.S., Dixon, M.A., \& Lin, Y.C. (2012). Roles and tasks of the senior woman administrator in role congruity theory perspective: A longitudinal progress report. Journal of Issues in Intercollegiate Athletics, 5, 247-268.

Trail, G., \& Chelladurai, P. (2000). Perceptions of goals and processes of intercollegiate athletics: A case study. Journal of Sport Management, 14(2), 154-178.

Umbach, P.D., Palmer, M.M., Kuh, G.D., \& Hannah, S.J. (2006). Intercollegiate athletes and effective educational practices: Winning combination or losing effort? Research in Higher Education, 47(6), 709-733. doi:10.1007/s11162-006-9012-9 
Valentine, J.J., \& Taub, D.J. (1999). Responding to the developmental needs of student athletes. Journal of College Counseling, 2(2), 164-179. doi:10.1002/j.2161-1882.1999. tb00153.x

Warner, S., \& Dixon, M.A. (2013). Sport and community on campus: Constructing a sport experience that matters. Journal of College Student Development, 54(3), 283-298. doi:10.1353/csd.2013.0044

Wicker, P., \& Breuer, C. (2011). Scarcity of resources in German non-profit sport clubs. Sport Management Review, 14(2), 188-201. doi:10.1016/j.smr.2010.09.001

Wicker, P., \& Breuer, C. (2013). Understanding the importance of organizational resources to explain organizational problems. VOLUNTAS: International Journal of Voluntary and Nonprofit Organizations, 24(2), 461-484. doi:10.1007/s11266-012-9272-2

Wicker, P., Breuer, C., \& Hennigs, B. (2012). Understanding the interactions among revenue categories using elasticity measures: Evidence from a longitudinal sample of non-profit sport clubs in Germany. Sport Management Review, 15(3), 318-329. doi:10.1016/j. smr.2011.12.004

Wicker, P., Vos, S., Scheerder, J., \& Breuer, C. (2013). The link between resource problems and interorganisational relationships: a quantitative study of Western European sport clubs. Managing Leisure, 18(1), 31-45. doi:10.1080/13606719.2012.742226

Wolfe, R.A., Hoeber, L., \& Babiak, K. (2002). Perceptions of the effectiveness of sport organisations: The case of intercollegiate athletics. European Sport Management Quarterly, 2(2), 135-156. doi:10.1080/16184740208721917 